\title{
Fourteen Days Post-Ovariectomy Estrogens Decline Is Associated with Anxiogenic Effects on Wistar Rats
}

\author{
Zemo Gamo Franklin ${ }^{1}$, Djiogue Sefirin ${ }^{1}$, Ketcha Wanda Germain Jean Magloire ${ }^{2}$, Seke Etet Paul Faustin ${ }^{3}$, \\ Yonkeu Tatchou Floriane Gaëlle ${ }^{1}$, Djikem Tadah Rudig Nikanor ${ }^{1}$, Awounfack Charline Florence ${ }^{1}$ and Njamen \\ Dieudonne ${ }^{1}$ \\ 1. Department of Animal Biology and Physiology, Faculty of Science, University of Yaounde I, Yaounde P.O. Box 812, Cameroon \\ 2. Department of Psychology, Faculty of Arts, Letters and Social Science, University of Yaounde I, Yaounde P.O. Box 7011, \\ Cameroon \\ 3. Department of Basic Health Sciences, College of Applied Medical Sciences, Qassim University, Al-Qaseem 51452, Saudi Arabia
}

\begin{abstract}
On study of the effects of estrogen deficiency on anxiety disorder by using ovariectomised animals, one discrepancy was the difference in behavioral testing delay following ovariectomy and the paradigms used. Thus, the aim of this study was to evaluate the anxiogenic effects of fourteen-day estrogen decline subsequent to ovariectomy on Wistar rats using EPM (elevated plus-maze) and open field tests. As results, fourteen days of estrogens decline has induced an increase of anxiety-related behaviour by a reduction of the percentage of the number of entries into the open arm $(p<0.01)$ and an increase of the percentage of the number of entries into the closed arm $(p<0.01)$ during the elevated plus-maze test. This anxiety-like behaviour was confirmed on the open field test by a reduction of time spent in the centre of the arena $(p<0.05)$ as well as a reduction of crossing $(p<0.05)$ and an increase of the weight of faecal boli $(p<0.05)$ and grooming $(p<0.01)$. Meanwhile, the administration of diazepam or estradiol valerate $(1 \mathrm{mg} / \mathrm{kg} \mathrm{BW}$ each) has corrected the anxious-like behaviour in both tests paradigms. These results suggest that fourteen days of estrogens decline was associated with an anxiety-related behaviour. This experimental model can constitute an excellent tool for the study of anxiolytic substances in menopause-related anxiety.
\end{abstract}

Key words: Ovariectomy, estrogen decline, anxiety, EPM, open field.

\section{Introduction}

Menopause is defined as cessation of menstruation due to endogenous estrogen deficiency subsequent to ovarian follicles depletion. To the female endocrine system, estrogens are steroid hormones produced principally by the ovaries from puberty. Their action is to regulate the growth and the development of reproductive organs as well as the homeostasis of a variety of tissues [1]. The 17ß-estradiol (E2) can have profound effects on women's physiological and/or psychological function. At menopause, these effects of E2 appear most evidently with its drastic decline due to ovarian follicles depletion. About $75 \%$ of women

Corresponding author: Sefirin Djiogue, Ph.D., senior lecturer, research fields: Physiology and Pharmacology. experience negative physical (hot flashes, night sweats, vaginal mucosa dryness) and/or psychological/quality-of-life (forgetfulness, anxiety, depression, sleeplessness, reduced sex drive) symptoms [2].

Nervous system ailments such as anxiety are among the most invalidating of all the diseases assigning Human. Statistically, between $10 \%$ of the world population suffered from several forms of anxiety [3], furthermore, considering the fact that the world population aged above 65 years old is expected to rise to 973 million by 2026 [4], about $20 \%$ of the adult population will have suffer from anxiety at least once in its lifespan. Thus it makes anxiety to be one of the main focuses of the psychopharmacology research this last decade. At menopause, this pathology is 
accentuated and approximately $10 \%$ to $25 \%$ of women suffering from such ailment affected the nervous system seek a treatment [5].

The classic treatment of anxiety-related ailments is the use of benzodiazepines. However, these psychotropic agents seem not appropriate for the primary treatment of symptoms associated to a lack of estrogens [6]. The HRT (hormone replacement therapy) remains the principle treatment for menopause related symptoms. Despite the effectiveness of hormone replacement therapy to alleviate menopause symptoms, many women refuse or discontinue treatment because of the adverse effects such as an increased risk of cancer and cardiovascular diseases [7, 8]. Following this, the needs for developing new alternative treatments for the management of physiological and/or psychological disorders related to menopause remain urgent [5]. Several experimental models have been used to test the efficacy of different alternative treatments. There are some evidences from animal studies that support the critical period hypothesis. An approach that is often utilized to begin to determine functional effects of ovarian cessation (e.g. postmenopausal osteoporosis, psychological changes) is surgical removal of the ovaries (ovariectomy: OVX). The duration of estrogen deprivation may be an important factor that influences the appearance of psychological symptoms. Some studies report that aged female mice respond favourably to E2 administration and exhibit greater anti-anxiety and antidepressant behaviour [9].

Ovariectomized animals have frequently been used to study the effects of estrogen deficiency on mood disorders, particularly anxiety disorder. One discrepancy was the difference in behavioural testing time following ovariectomy and the paradigms used. Therefore, the aim of this study was to evaluate the impact of fourteen days of estrogens depletion on ovariectomized Wistar rats using the elevated plus-maze and the open field tests.

\section{Material and Methods}

\subsection{Animals}

Juvenile female Wistar rats, $150 \pm 10 \mathrm{~g}$, between 10 and 12 weeks old were used for this study. The animals were housed in the animal facility of the Laboratory of Animal Physiology, University of Yaoundé 1 (temperature $25-28{ }^{\circ} \mathrm{C}$; humidity $50-80 \% ; 12 \mathrm{~h}$ light-dark cycles). They had free access to a standard soy-free rat diet (SSniff GmbH, Soest, Germany) and were provided tap water ad libitum. The research was conducted in accordance with the European Commission Guidelines for Laboratory Animal Use and Care (EEC Directive of 1986; 86/609/EEC).

\subsection{Chemicals}

Diazepam (Valium ${ }^{\circledR} 10 \mathrm{mg} / 2 \mathrm{~mL}$, laboratoire Roche, Fontenay-sous-bois, France, Diaz) and estradiol valerate (Progynova ${ }^{\circledR} 2 \mathrm{mg}$, DEL-PHARM, Lille, France, E2V) were used as reference drugs.

\subsection{Experimental Design}

Before each test, all female Wistar rats were ovariectomised except the Sham rats. The bilaterally ovariectomized (OVX) using the dorsal approach [10] under diazepam and ketamin anesthesia (respectively $10 \mathrm{mg} / \mathrm{kg}$ and $50 \mathrm{mg} / \mathrm{kg} \mathrm{BW}$; i.p.) was used. After fourteen days of endogenous hormonal decline [11], animals were randomly organized into groups for the tests. Animals were acclimated three days in the testing room before the experiments. The animals were randomly divided into four groups and each group consisting of five animals: the NOVX group (Sham operated received the vehicle: distilled water, p.o.), OVX group (negative control received the vehicle, p.o.), E2V group (positive control group received $17 \beta$-estradiol at $1 \mathrm{mg} / \mathrm{kg}$, p.o.) and Diaz group (positive control received at $1 \mathrm{mg} / \mathrm{kg}$, i.p.). One hour following the administration of different substances $(1 \mathrm{~mL} / 100 \mathrm{~g}$ BW for oral administration), each rat was observed for 
a period of $5 \mathrm{~min}$. Between two tests, the maze was cleaned with $70 \%$ ethanol solution and dry cloth to avoid perturbation of the animals due to urine and faeces. For each paradigm, the data were collected with a video-camera system and a new set of animals was used. The tests were done in a room under the normal day light between 8 am and 4 pm.

After different tests, the treatment of animal continues for the next two days. This was to confirm the effects of estrogen decline and substances administration. According to Ref. [11], estrogenic effects of substance can be observed after three days of treatment.

\subsubsection{EPM (Elevated Plus-Maze) Test}

EPM is the simplest apparatus to study anxiolytic response of almost all types of anti-anxiety agents. The elevated plus maze produced a novel environment which helped in inducing anxiety in animals because of the open nature of the arms and elevation from the floor. The maze consisted of two opposite open arms $(50 \mathrm{~cm}$ $\times 15 \mathrm{~cm}$ ), crossed with two enclosed arms of the same dimensions with walls $50 \mathrm{~cm}$ high. The arms were connected with a central square, $15 \mathrm{~cm} \times 15 \mathrm{~cm}$ to give the apparatus a plus sign appearance. The maze was elevated $71 \mathrm{~cm}$ above the floor in a dimly lit room. Rodents have a natural aversion for high and open spaces and prefer enclosed arms and showed anxiety and fear like movements characterized by immobility. When exposed to the novel maze alley, the animals experience an approach-avoidance conflict, which is stronger in the open arm as compared to the enclosed arms.

For the test, each rat was placed individually at the corner of an open arm observed and the parameters noted were time spent in open/closed arms, number of entries in the open/closed arms, number of rearing, number of head dipping and number of grooming [12, 13]. The percentages of times spent and the number of entries in each type of arms was calculated for each animal.

\subsubsection{Open Field Test}

The OF (open field) used was consisted of a wooden square box $60 \times 60 \times 40 \mathrm{~cm}$; the floor was divided into 16 smaller squares of equal dimensions $(15 \times 15 \mathrm{~cm})$. To evaluate exploratory activity and anxiety, the animals were placed one by one at the centre of the box and the parameters noted were the number of crossing, time spent in the centre, number of rearing, weight of faecal boli and number of grooming.

\subsection{Histological Analysis}

Using the complete Zeiss equipment consisting of a microscope (Axioskop 40) connected to a computer where the image (400 X) was transferred and analyzed with the MRGrab1.0 and Axio Vision 3.1 software, all provided by Zeiss (Hallbermoos, Germany) [14]; the histomorphology of the mammary glands, as well as the uterine and vaginal epithelial heights, was assessed from $5-\mu \mathrm{m}$ sections of paraffin-embedded tissues following hematoxylin—eosin staining.

\subsection{Statistical Analysis}

The data from each experimental group were expressed as the mean \pm S.E.M. The significance of the difference between treated groups and OVX group or Sham (NOVX) group was determined using one-way ANOVA followed by Dunnett's test and the significance of the difference between OVX group and NOVX group was determined using the Mann-Whitney test (GraphPad Prism, version 5.03). The $p$-value $<0.05$ was considered significant.

\section{Results and Discussion}

The menopause is the permanent cessation of the menses which marks the end of the reproductive cycle of the woman and is characterized by a drastic drop in circulating estrogens. This situation is responsible of significant metabolic changes causing much pathology on various tissues and systems such as depression and anxiety $[5,15,16]$. Anxiolytics are compounds used to 
fight the psychic and somatic components of the anxiety. Some treatments exist but are not appropriate or have many adverse effects in menopausal women. Phytoestrogens are natural polyphenolic plant-derived compounds with estrogenic or anti-estrogenic properties [17] and some studies shows that their use can have protective effects on diseases due to the deficiency in estrogens [18]. The anxiolytic effects of phytoestrogen can be the result of its action on ER (estrogens receptors) and/or GABAA receptors on his steroids site [19, 20]. Phytoestrogens can constitute an alternative and it is important to have an experimental model to study their anxiolytic effects in menopause-related anxiety.

To evaluate anxiety-like behaviour on ovariectomised rats after the fourteen days of estrogen decline, the EPM test was used. It is the most commonly used test to study anxiolytic response of almost all types of anti-anxiety agents [21]. The results obtained in our investigation with the EPM test (Table 1) showed that ovariectomy induces an increase of the percentage of closed arms entries $(p<0.01)$ and time spent in the same arms. In the open arms, a decrease of the same parameters was observed. All these effects reflect a decrease of open arms exploration and showed the anxiogenic responses of ovariectomy in the EPM. As shown in Table 1, these anxiogenic effects of ovariectomy are also materialized by an increase of grooming and a decrease of head dipping and rearing compare to NOVX group. In the literature several authors showed that on the evaluation of the anxious parameters, an animal which explores the open arms is described as "not very anxious" and the animal that remains confined in the closed arms of the EPM is "anxious". In the same way the increase in the number of grooming directly reflects an increase of anxiety and the reduction in the number of head dipping and number of rearing shows an increase of stress [20-23]. These results suggest those ovariectomysed animals are more anxious than none ovariectomised. Comparing to OVX group, Diazepam an E2V treatments at the dose of $1 \mathrm{mg} / \mathrm{kg}$ BW each corrected all these parameters (Table 1). Some authors have shown that substances such as diazepam and $17 \beta$-estradiol are able to increase the open arm exploratory behaviour in the EPM test in rodents, and thus exhibit anxiolytic activity [13, 24-26]. These anxiolytic properties could result from the action of these compounds on GABA (gamma amino-butyric acid) receptors complex [27]. The E2V, a steroid compound, can activate GABAA receptors on his steroids site fixation [19] and the ER $\beta$ that plays a major role in the regulation of the anxiety in the brain $[20,28]$.

Menopause-related anxiety was confirmed by the open field test. As regards the results obtained (Table 2), the ovariectomy induced a reduction of the number of crossing $(p<0.05)$, time spent in the centre

Table 1 Effects of fourteen days of estrogen decline and E2V/Diaz treatment on different parameters evaluated by the EPM test.

\begin{tabular}{lllll}
\hline Parameters & NOVX & OVX & E2V & Diaz \\
\hline Time spent in the open arms (\%) & $1.25 \pm 0.71$ & $0.00 \pm 0.00$ & $18.80 \pm 4.45^{* *}$ & $32.63 \pm 3.75^{* * *}$ \\
Time spent in the closed arms (\%) & $98.75 \pm 0.71$ & $100.00 \pm 0.00$ & $81.20 \pm 4.45^{* *}$ & $67.37 \pm 3.75^{* * *}$ \\
Number of entries into open arms (\%) & $28.00 \pm 5.61$ & $0.00 \pm 0.00 \# \#$ & $38.57 \pm 6.27^{* * *}$ & $50.00 \pm 5.27^{* * *}$ \\
Number of entries into closed arms (\%) & $72.00 \pm 5.61$ & $100.00 \pm 0.00 \# \#$ & $61.43 \pm 6.27^{* * *}$ & $50.00 \pm 5.27^{* * *}$ \\
Rearing & $7.00 \pm 1.38$ & $4.80 \pm 0.20$ & $13.40 \pm 1.29^{* * *}$ & $8.60 \pm 0.81^{*}$ \\
Head dipping & $2.00 \pm 0.45$ & $1.00 \pm 0.55$ & $2.20 \pm 0.49$ & $3.00 \pm 0.84$ \\
Grooming & $2.80 \pm 0.37$ & $3.60 \pm 0.60$ & $2.20 \pm 0.20$ & $2.80 \pm 0.58$ \\
\hline
\end{tabular}

Data are expressed as mean \pm SEM, $\mathrm{n}=5$ per group. NOVX $=$ Sham operated animals treated with the vehicle, OVX $=$ OVX animals treated with the vehicle, E2V = OVX animals treated with estradiol valerate at $1 \mathrm{mg} / \mathrm{kg} \mathrm{BW}$, Diaz $=$ OVX animals treated with diazepam $1 \mathrm{mg} / \mathrm{kg} \mathrm{BW}$. And ${ }^{*} p<0.05,{ }^{* *} p<0.01,{ }^{* * *} p<0.001 \mathrm{vs.} \mathrm{OVX}$ (one-way ANOVA followed by Dunnett's test), \#\#p $<0.01$ vs. NOVX (Mann-Whitney test). 
of the paradigm $(p<0.05)$ and number of rearing compared to NOVX group. Moreover, the ovariectomy induced a significant increase in the mass of fecal boli $(p<0.05)$ and number of grooming $(p<0.01)$ in comparison which NOVX group as shown in Table 2. In the literature several authors show that an animal which spends more time in the centre of the open field is "not very anxious" whereas an animal which spends less time in the centre of the device is regarded as being "anxious". As suggested by Augustsson 2004 [29], the decrease of time spent at the centre show a reduction in the locomotory activity and the level of exploration and consequently an increase of anxiety. Moreover, Ngo Bum et al. [30] and Rodger et al. [31] showed that animals present a decreases of crossing and increase of the mass of fecal boli under the conditions of stress that the open field imposes is anxious. In the same way the increase in the number of grooming directly reflects an increase of anxiety. These results suggest that OVX animals would be more anxious than those not ovariectomised (NOVX). Compared to OVX group, Diazepam an E2V treatments at the dose of $1 \mathrm{mg} / \mathrm{kg}$
BW each corrected all these parameters (Table 2). The anxiolytic properties of these substances could result from their action on GABA-receptors complex or the ER $\beta$ as previously described in the EPM test $[19,20$, $27,28]$.

The results obtained after three days of treatment showed that the ovariectomy induced a significant reduction of the vaginal epithelial height $(p<0.05)$, uterine wet weight $(p<0.01)$, uterine epithelium height $(p<0.05)$, total protein levels $(p<0.05)$ and inhibit the eosinophilic secretion on the mammary gland in comparison with NOVX group (Table 3; Figs. 1-3). These results are in accordance which works done by Njamen et al. [14] and Westwood [32]. For these authors, fourteen days of estrogens decline after ovariectomy induced an atrophy of the vaginal epithelium, the reduction of the uterine wet weight, uterine epithelium height and total protein levels in this uterine. The results are also in agreement with those of Bocchinfuso et al. [33] and Zingue et al. [34] which have shown that in the mammary glands ovariectomy induces a stop of the production of eosinophilic secretion

Table 2 Effects of fourteen days of estrogen decline and E2V/Diaz treatment on different parameters evaluate by the open field test.

\begin{tabular}{lllll}
\hline Parameters & NOVX & OVX & E2V & Diaz \\
\hline Crossing & $72.40 \pm 5.23$ & $38.20 \pm 5.87 \#$ & $50.80 \pm 1.96$ & $85.00 \pm 12.68^{* *}$ \\
Time spent in the center (s) & $10.40 \pm 0.68$ & $4.80 \pm 1.16 \#$ & $8.00 \pm 1.64$ & $12.80 \pm 1.88^{* *}$ \\
Rearing & $10.80 \pm 1.59$ & $7.60 \pm 0.93$ & $11.00 \pm 0.32^{*}$ & $12.20 \pm 1.07^{* *}$ \\
Weight of fecal boli (g) & $3.60 \pm 0.93$ & $5.40 \pm 0.24 \#$ & $3.20 \pm 0.49^{* *}$ & $2.60 \pm 0.40^{* * *}$ \\
Grooming & $0.86 \pm 0.10$ & $1.73 \pm 0.19 \# \#$ & $1.50 \pm 0.17$ & $1.43 \pm 0.36$ \\
\hline
\end{tabular}

Data are expressed as mean \pm SEM, $n=5$ per group. NOVX $=$ Sham operated animals treated with the vehicle, OVX $=$ OVX animals treated with the vehicle, E2V $=$ OVX animals treated with estradiol valerate at $1 \mathrm{mg} / \mathrm{kg} \mathrm{BW}$, Diaz $=$ OVX animals treated with diazepam $1 \mathrm{mg} / \mathrm{kg} \mathrm{BW}$. And ${ }^{*} p<0.05,{ }^{*} p<0.01,{ }^{* * *} p<0.001$ vs. OVX (one-way ANOVA followed by Dunnett's test), \#p $<0.05$, $\#$ \# $<0.01$ vs. NOVX (Mann-Whitney test).

Table 3 Effect of fourteen days of estrogen decline and E2V/Diaz treatment on different estrogen target organs.

\begin{tabular}{lllll}
\hline Parameters & NOVX & OVX & E2V & Diaz \\
\hline Vaginal epithelial height $(\mu \mathrm{m})$ & $24.37 \pm 5.42$ & $6.25 \pm 0.59 \#$ & $40.13 \pm 4.36^{* * *}$ & $10.08 \pm 1.74$ \\
Relative uterine wet weight $(\mathrm{mg} / \mathrm{kg} \mathrm{BW})$ & $1067.18 \pm 116.86$ & $458.00 \pm 18.45 \# \#$ & $1448.78 \pm 163.59^{* * * *} 481.44 \pm 20.00$ \\
Uterine epithelial height $(\mu \mathrm{m})$ & $6.54 \pm 0.70$ & $2.73 \pm 0.26 \#$ & $7.34 \pm 0.60^{* * *}$ & $3.14 \pm 0.31$ \\
Total protein levels in uterine $(\mathrm{mg} / \mathrm{ml})$ & $0.39 \pm 0.07$ & $0.19 \pm 0.03 \#$ & $0.61 \pm 0.02 * * *$ & $0.30 \pm 0.05$ \\
\hline
\end{tabular}

Data are expressed as mean \pm SEM, $n=5$ per group. NOVX $=$ Sham operated animals treated with the vehicle, OVX $=$ OVX animals treated with the vehicle, E2V $=$ OVX animals treated with estradiol valerate at $1 \mathrm{mg} / \mathrm{kg} \mathrm{BW}$, Diaz $=$ OVX animals treated with diazepam $1 \mathrm{mg} / \mathrm{kg} \mathrm{BW}$. And ${ }^{* * *} p<0.001$ vs. OVX (one-way ANOVA followed by Dunnett's test), \#p $<0.05$, \#\#p $<0.01 \mathrm{vs.} \mathrm{NOVX}$ (Mann-Whitney test). 

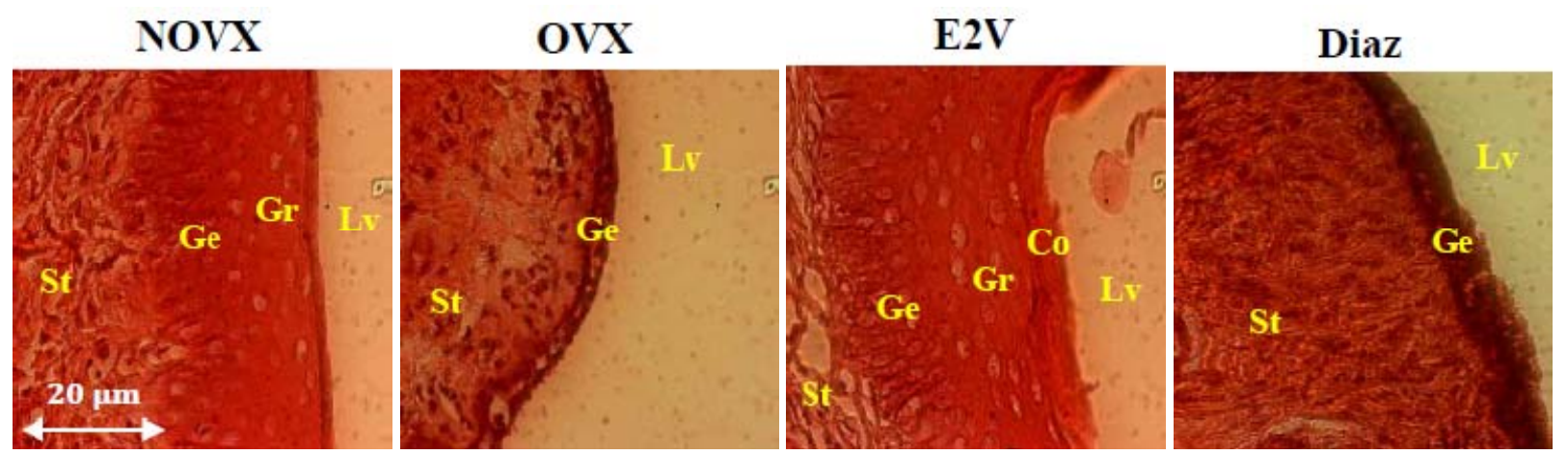

Fig. 1 Microphotographs $(400 \mathrm{X})$ of the vaginal epithelial after fourteen days of estrogen depletion.

NOVX $=$ Sham operated animals treated with the vehicle, OVX $=$ OVX animals treated with the vehicle, E2V $=$ OVX animals treated with estradiol valerate at $1 \mathrm{mg} / \mathrm{kg} \mathrm{BW}, \mathrm{Diaz}=\mathrm{OVX}$ animals treated with diazepam $1 \mathrm{mg} / \mathrm{kg} \mathrm{BW} . \mathrm{Lv}=$ vaginal lumen, Co $=$ stratum corneum, $\mathrm{Gr}=$ stratum granulosum, $\mathrm{Ge}=$ stratum germinativum, $\mathrm{St}=$ Stroma.
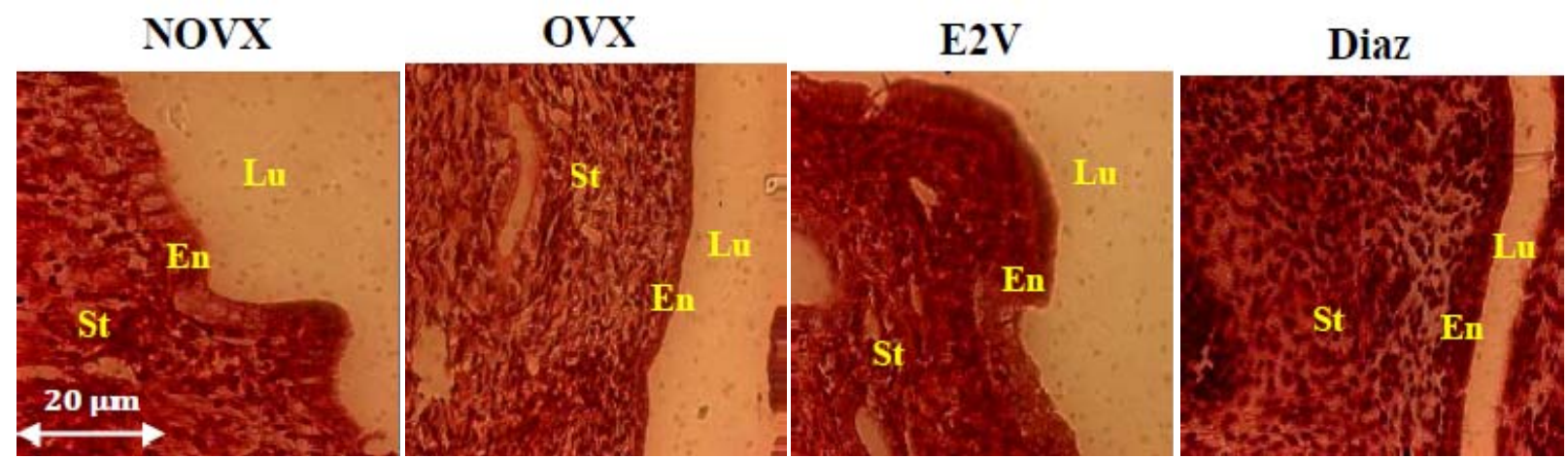

Fig. 2 Microphotographs $(400 \mathrm{X})$ of the uterine epithelial after fourteen days of estrogen depletion.

NOVX $=$ Sham operated animals treated with the vehicle, OVX $=$ OVX animals treated with the vehicle, E2V $=$ OVX animals treated with estradiol valerate at $1 \mathrm{mg} / \mathrm{kg} \mathrm{BW}$, Diaz $=\mathrm{OVX}$ animals treated with diazepam $1 \mathrm{mg} / \mathrm{kg} \mathrm{BW}$. Lu: uterine lumen; En: Endometrium; St: Stroma.
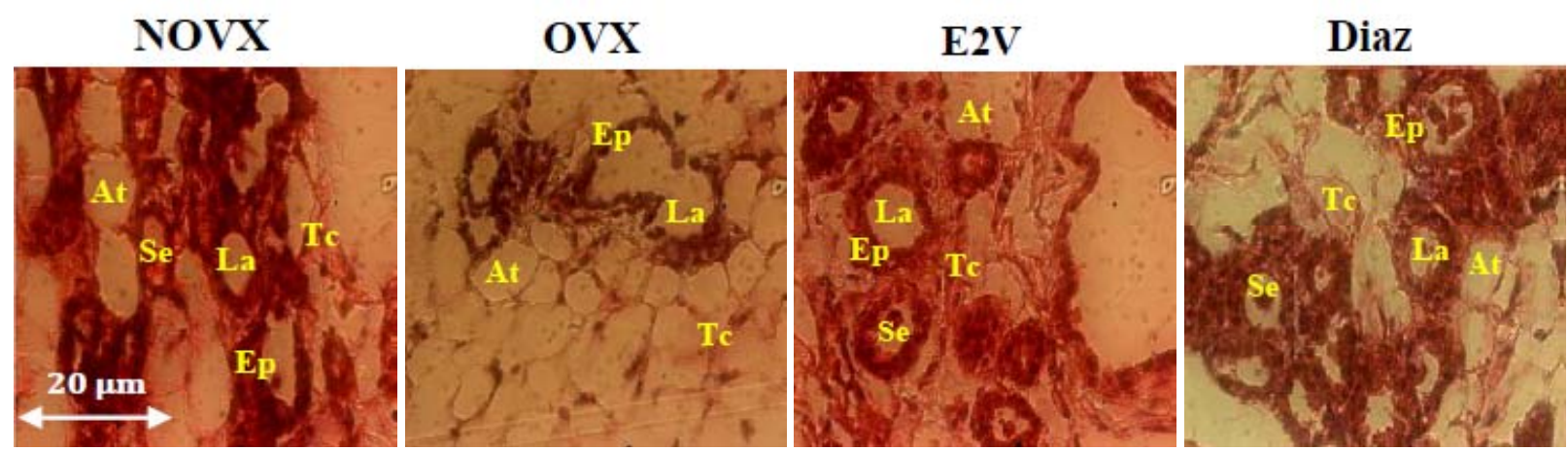

Fig. 3 Microphotographs $(400 \mathrm{X})$ of the mammary gland after fourteen days of estrogen depletion.

$\mathrm{NOVX}=$ Sham operated animals treated with the vehicle, OVX $=$ OVX animals treated with the vehicle, E2V $=$ OVX animals treated with estradiol valerate at $1 \mathrm{mg} / \mathrm{kg} \mathrm{BW}, \mathrm{Diaz}=\mathrm{OVX}$ animals treated with diazepam $1 \mathrm{mg} / \mathrm{kg} \mathrm{BW}$. La = lumen of alveoli, Ep = aveoli epithelium, At = adiposite tissue, $\mathrm{Tc}=$ gland parenchyma, $\mathrm{Se}=$ eosinophil secretion.

in the lumen of alveoli. These results suggest that estrogen decline was induced fourteen days after ovariectomy. As shown in (Table 3; Figs. 1-3) the E2V treatment at the dose of $1 \mathrm{mg} / \mathrm{kg} \mathrm{BW}$ has corrected all these effects induced by ovariectomy ( $p<0.001)$. Several authors have shown that estrogenic substances are able to regulate the physiological changes of estrogen target organs due to estrogen deficiency. 
Taken together, these observations show that the menopausal statue of ovariectomised rat is obtained. The diazepam, an anxiolytic substance does not have any significant effect on estrogen target organ compared to OVX group. This is why diazepam may not be appropriate to manage anxiety due to estrogen decline.

\section{Conclusions}

The findings of this study have shown that fourteen days of estrogens' depletion in ovariectomised Wistar rats was followed by an appearance of anxiety. Additionally, DZP and E2V at the dose of $1 \mathrm{mg} / \mathrm{kg} \mathrm{BW}$ each as anxiolytic referee drugs have abolished the observed anxiety. This experimental model can constitute an excellent tool for the study of anxiolytic substances in menopausis-related anxiety. Knowing that the duration of estrogen deprivation may be an important factor that influences the appearance of psychological symptoms, we report here for the first time that fourteen-day post-oophorectomy is enough for the anxiety-like symptoms to be installed.

\section{Acknowledgments}

The authors are thankful to the members of the Laboratory of Animal Physiology of the University of Yaoundé 1 for their technical assistance.

\section{References}

[1] Agatonovic-Kustrin, S., Turner, J. V., and Glass, B. D. 2008. "Molecular Structural Characteristics as Determinants of Estrogen Receptor Selectivity.” J. Pharm Biomed Anal 48: 369-75.

[2] Walf, A. A., Paris, J. J., and Frye, C. A. 2009. "Chronic Estradiol Replacement to Aged Female Rats Reduces Anxiety-Like and Depression-Like Behavior and Enhances Cognitive performance.” Psychoneuroendocrinology 34: 909-16.

[3] WHO. 2001. "Mental and Neurological Disorders.” Fact Sheet 25.

[4] Kinsella, K., and Velkoff, V. 2001. "An Aging World: 2001.” U.S. Census Bureau, Series P95/01-1. U.S. Gorvernment Printing Office, Washington, DC.

[5] Doyle, B. J., Frasor, J., Bellows, L. E., Locklear, T. D., Perez, A., Gomez-Laurito, J., and Mahady, G. B. 2009.
"Estrogenic Effects of Herbal Medicines from Costa Rica Used for the Management of Menopausal Symptoms." Menopause 16: 748-55.

[6] Albertazzi, P. 2007. "Non-estrogenic Approaches for the Treatment of Climacteric Symptoms.” Climacteric 10: 115-20.

[7] Ito, K. 2007. "Hormone Replacement Therapy and Cancers: The Biological Roles of Estrogen and Progestin in Tumorigenesis are Different between the Endometrium and Breast.” Tohoku J. Exp Med. 212: 1-12.

[8] Scheid, V. 2007. "Traditional Chinese Medicine-What Are We Investigating? The Case of Menopause.” Complement Ther. Med. 15: 54-68.

[9] Walf, A. A., and Frye, C. A. 2010. "Estradiol Reduces Anxiety- and Depression-Like Behavior of Aged Female Mice.” Physiology and Behavior 99: 169-74.

[10] Lane, N. E., Yao, W., Kinney, J. H., Modin, G., Balooch, M., and Wronski, T. J. 2003. "Both hPTH (1-34) and bFGF Increase Trabecular Bone Mass in Osteopenic Rats but They Have Different Effects on Trabecular Bone Architecture.” J Bone Miner Res 18: 2105 - 2115.

[11] OECD. 2007. "Third Meeting of the Validation Management Group for the Screening and Testing of Endocrine Disrupters (Mammalian Effects).” Joint Meeting of the Chemicals Committee and the Working Party on Chemical, Pesticides and Biotechnology. http://www.oecd.org.

[12] Casarrubea, M., Magnusson, M. S., Roy, V., Arabo, A., Sorbera, F., Santangelo, A., and Crescimanno, G. 2012. Temporal Patterns of Rodent Behavior in the Elevated Plus Maze Test. Eds. Spink, A. J., Grieco, F., Krips, O. E., Loijens, L. W. S., Noldus, L. P. J. J., and Zimmerman, P. H., 350.

[13] Ketcha, G. J. M., Djiogue, S., Zemo, G. F., Guemnag, G. S., and Njamen, D. 2015. "Anxiolytic and Sedative Activities of Aqueous Leaf Extract of Dichrocephala integrifolia (Asteraceae) in Mice.” J. Ethnopharmacol 176: 494-8.

[14] Njamen, D., Magne Nde, C. B., Fomum, Z. T., and Mbanya, J. C. 2007. "Preventive Effects of an Extract of Erythrina lysistemon (Fabaceae) on Some Menopausal Problems: Studies on the Rat.” J. Complement Integr. Med. 4: 1-6.

[15] Pinkerton, J. V., Stovall, D. W., and Kighlinger, R. S. 2009. "Advances in the Treatment of Menopausal Symptoms." Womens Health 5: 361-84.

[16] Deepak, P. S., Kevin, M. W., and Peter, P. 2013. “Insights into Rapid Modulation of Neuroplasticity by Brain Estrogens.” Pharmacol Rev. 65: 1318-50.

[17] Umland, E. M., Cauffield, J. S., Kirk, J. K., and Thomason, T. E. 2000. "Phytoestrogens as therapeutic Alternatives to Traditional Hormone Replacement in Postmenopausal Women.” Pharmacotherapy 20: 981-90. 
[18] Ferrari, A. 2009. "Soy Extract Phytoestrogens with High Dose of Isoflavones for Menopausal Symptoms.” J. Obstet Gynaecol Re. 35: 1083-090.

[19] Daendee, S., Thongsong, B., and Kalandakanond-Thongsong, S. 2013. "Effects of Time of Estrogen Deprivation on Anxiety-Like Behavior and GABAA Receptor Plasticity in Ovariectomized Rats.” Behav Brain Res. 246: 86-93.

[20] Lund, T. D., Rovis, T., Chung, W. C., and Handa, R. J. 2005. "Novel Actions of Estrogen Receptor-Beta on Anxiety-Related Behaviors." Endocrinology 146: 797-807.

[21] Rodgers, R. J., and Dalvi, A., 1997. “Anxiety, Defence and the Elevated Plus-Maze.” Neuroscin. Biobehav. Rev. 21: 801-10.

[22] Lister, R. G. 1999. "Ethologically Based Animal Models of Anxiety Disorders.” Pharmacol Ther. 46: 321-40.

[23] Oviedo, V. M., Milded, G. G., Rincon, J., and Guerrero, M. F. 2006. "Effect of an Extract of Annona muricata on Central Nervous System.” Pharmacologyonline 3: 342-7.

[24] Walf, A. A., and Frye, C. A., 2007. "The Use of the Elevated Plus-Maze as an Assay of Anxiety-Related Behavior in Rodents.” Nat. Protoc. 2: 322-8.

[25] Adeyemi, O. O., Akindele, A. J., Yemitan, O. K., Aigbe, F. R., and Fagbo, F. I. 2010. "Anticonvulsant, Anxiolytic and Sedative Activities of the Aqueous Root Extract of Securidacalon gepedunculata Fresen.” J. Ethnopharmacol 130: 19-195.

[26] Janaine, M. C., Renata, L., Lucas, G., João, C. P. M., and Rúbia, M. W. O. 2011. "Preclinical Evaluation of Trichilia catigua Extracts on the Central Nervous System of Mice.” J. Ethnopharmacol 137: 1143-8.
[27] Xiu-Yan, W., Jing-Yu, Y., Jim-Hui, W., and Chun-Fu W. 2007. "Anxiolytic Effect of Saponins from Panax quinquefolium in Mice.” J. Ethnopharmacol 111: 613.

[28] Cheryl, S. W., Rebecca, A. A., Kathryn, A. C., and Yow-Jiun, J. 2010. "Estrogens of Multiple Classes and Their Role in Mental Health Disease Mechanisms.” Inter. J. Women's Health 2: 153-66.

[29] Augustsson, H. 2004. "Ethoexperimental Studies of Bihaviour in Wild and Labora-tory Mice. Risk Assessment, Emotional Reactivity and Animal Welfare.” Doctoral thesis, Swedish University of Agricultural Sciences.

[30] Ngo Bum, E., Taiwe, G. S., Moto, F. C. O., Ngoupaye, G. T., Nkantchoua, G. C. N., Pelanken, M. M., Rakotonirina, A., and Rakotonirina, S. V. 2009. "Anticonvulsant, Anxiolytic and Sedative Properties of the Roots of Nauclea latifolia in Mice.” Epilepsy Behav. 15: 434-40.

[31] Rodger, R. J., Cao, B.-J., Dalvi, A., and Holmes, A. 1997. “Animal Models of Anxiety: An Ethological Perspective." Brazilian J. Med. Bilogy. Res. 30: 289-304.

[32] Westwood, F. R. 2008. "The Female Rat Reproductive Cycle: A Practical Histological Guide to Staging.” Toxicol. Path 36: 375-84.

[33] Bocchinfuso, W. P., Lindzey, J. K., Hewitt, S. C., Clark, J. A., Myers, P. H., Cooper, R., and Korach, K. S. 2000. "Induction of Mammary Gland Development in Estrogen Receptor-Alpha Knockout Mice.” Endocrinol. 141: 2982-94.

[34] Zingue, S., Njamen, D., Tchoumtchoua, J., Halabalaki, M., Simpson, E., Clyne, C., and Magne Nde, C. B. 2013. "Effects of Millettia macrophylla (Fabaceae) Extracts on Estrogen Target Organs of Female Wistar Rat.” $J$ Pharmacol. Sci. 123: 120-31. 